\title{
Erratum to: Quality of Gluten-free Bread Formulations Baked in Different Ovens
}

\author{
Ilkem Demirkesen • Gulum Sumnu • Serpil Sahin • \\ Mehmet Musa Ozcan
}

Published online: 21 April 2013

(C) Springer Science+Business Media New York 2013

Erratum to: Food and Bioprocess Technology 6(3): 746-753

DOI 10.1007/s11947-011-0712-6

Correction is required on this paper. Please note that one author is missing and should be mentioned as above.

The online version of the original article can be found at http://dx.doi.org/ 10.1007/s11947-011-0712-6.

I. Demirkesen · G. Sumnu $(\bowtie) \cdot$ S. Sahin

Department of Food Engineering,

Middle East Technical University, 06800 Ankara, Turkey

e-mail: gulum@metu.edu.tr

I. Demirkesen

Department of Food Engineering, On Dokuz Mayıs University,

55139 Samsun, Turkey

M. M. Ozcan

Department of Food Engineering, Selcuk University,

42030 Konya, Turkey 